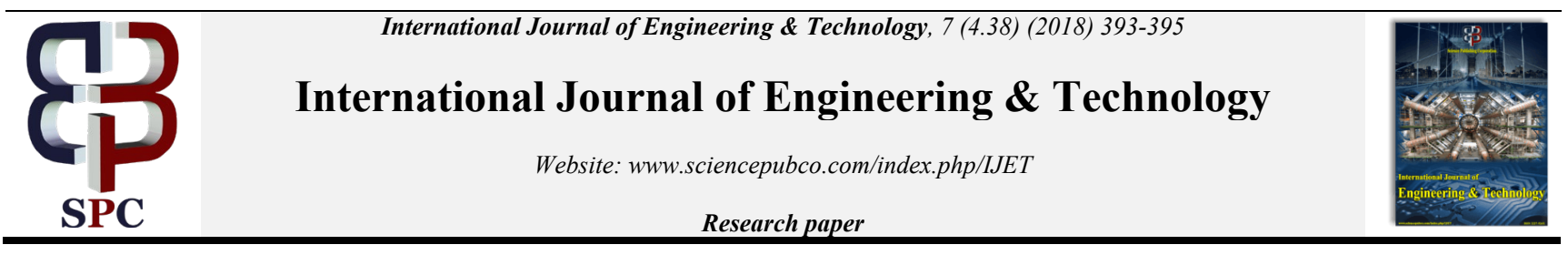

\title{
The Problem of Preparing Future Designers
}

\author{
A.A. Prishchepa ${ }^{1 *}$, L.A. Burovkina ${ }^{2}$, V.V. Koreshkov ${ }^{2}$ \\ ${ }^{\text {I} D o n ~ S t a t e ~ T e c h n i c a l ~ U n i v e r s i t y, ~ G a g a r i n a ~ S t r ., ~ 1, ~ R o s t o v-o n-D o n, ~ 344000, ~ R u s s i a ~}$ \\ ${ }^{2}$ Institute of Culture and Arts, Moscow City Pedagogical University, Selskokhozyastvennyy proezd, 2, Moscow, 129226, Russia \\ *Corresponding author E-mail: prishchepa.a.a@bk.ru
}

\begin{abstract}
The article is devoted to the study of professional training of future designers. The concepts of "competence", "professional competence" in the research of specialists are revealed. According to the authors, higher education is not a privilege, not the lot of the elected, but not a set of basic knowledge and skills. The diploma of higher education does not certify the identity or citizenship and not the rights and freedoms of the individual, but only the level of qualification in the specialty that requires fundamental scientific training. The system of higher education, unlike educational organizations, provides citizens with the special knowledge, skills and abilities required to replace well-defined places in the system of social division of labor. There are many professions in demand in the labor market and vital to society, the mastery of which requires training at the University and allows the individual to fully realize their abilities. The creation of a comfortable environment in higher education, helping young people to understand that in the pursuit of self-realization and achievement of success in life should be guided not by the prevailing stereotypes, and their own desires and inclinations, is a necessary condition for the successful professional development of the individual graduate.
\end{abstract}

Keywords: Competence, professional competence, design, competitiveness, artistic and creative activity.

\section{Introduction}

The educational process in the modern system of training designers is at a turning point in history. These objective conditions are comparable with the beginning of the twentieth century, that is, the stage of origin of design. The reformation of higher education is connected not only with changes in the structure of education, but also with the transformation and radical change of technologies not only of nano-technologies, industrial production technologies, but also educational technologies. Training a designer in modern conditions should be aimed at the future development of the industry, that is, what is not in the industry today and in educational technologies even more so. The fundamental change in technological processes, the introduction of 3D printers in production will require absolutely new strategic and tactical actions of the scientific community in the education system, and this is not only the reform of the administrative educational system, but also the formation of a new type of thinking. This problem includes the preparation of the designer with a new formative thinking, with a new operational system of logical actions and decision-making. "Today, the society needs highly qualified specialists. Currently, in a highly competitive market economy do not need low-skilled workers who do not possess professional competencies" [1].

Change of production capacities, transition to possibility of individual exclusive production of household items, necessary products, units and many other things will demand new approaches to design of design products. Design is an element of the system of material production, one of the necessary links, subject to the General laws of its functioning. The purpose of design, in General, is the production of material values, which on the basis of artistic design acquire artistic and aesthetic value. However, " neither the formal model nor the artistic theme is the only content of the work of art. All this is only means of artistic form" [2]. The era is not the production of consumer goods, and exclusive things, and the designer must be ready to develop and participate in the projects of the completed cycle in architecture, construction and industrial production. "The subject world of man is a product of design, it is design that determines his structure and character" [3]. The modern educational system should be the vanguard of ideas, new proposals for the formation and use of new trends, advanced ideas in the structure of socio-economic reforms.

The problem of modernization of higher education, which is currently being actively developed and is directly related to the need to improve the competitiveness of specialists, is currently being considered:

- through the prism of improving the quality of General and professional culture;

- change of old value orientations to new ones, taking into account the changed socio-political and economic relations in society;

- development of the ability to self-education.

On the one hand, the University education has a task to ensure maximum compliance with the international level of professional qualities of the designer, and on the other - to use the wide opportunities inherent in it to adapt art and pedagogical education to the specific conditions of the University, the needs and requirements of different categories of students in different educational contexts.

Therefore, the task of optimizing the training of designers is not only a strategic goal to meet, multiply and develop design experience at the level of European countries, but also to resolve internal contradictions in the educational system of Russia, as the competition among the leading Universities of the country during the reform is quite high.

The identified problem requires further theoretical, experimental and practical developments aimed at determining the degree of integration of special artistic disciplines in the development of 
professional competence of designers, holistic ideas about the expressiveness of the artistic language. "Global problems require generalized solutions that ... are rooted in decorativeness, monumentality and synthesis" [4].

\section{Review}

The social and cultural situation in the modern world and Russia calls to involve students through the possibility of their active participation in the solution of global problems of mankind, which contributes to the acquisition of young people appropriate system of values and the development of the ability to rapid change. From the point of view of personality, the epicenter of self-identification shifts from the field of professional skills towards the development of creative potential of self-realization and active process of mastering the world. Formation of such personal structures and development of such abilities which allow the person to be guided independently in cultural and educational space becomes rather necessary and important for the person. Future specialist must be prepared for the continuous learning process, which constantly accompanies the process of professional activity. The relevance of the studied problem is confirmed by the scientific works of S.M. Mikhailov, in which he describes the priority of design as a way of formation of professional competences, A.A. Prischepy, I.M. Vlasova, Sottass, Maarten van Severen [5]. Training future designers today is both an economic and a socio-cultural necessity. At one time, K.M. Kantor noted: "The creation of design theory is an act of self - knowledge, it is an opportunity for every designer to create meaningfully, not blindly, knowing that the best design can not give more than what he has" [6]. Professional training of specialists in higher education should include three levels: the level of highly specialized competence; the level of socioprofessional competence; level of individual and professional competence. The implementation of all three levels in the process of training in higher education will allow the graduate to successfully adapt to the modern dynamic world, be competitive, constantly engage in self-development and improve their skills, this is the basis of the professional success of the young specialist.

Thus, modern education is designed to prepare professionals who can easily learn, quickly adapt to changing conditions and the content of professional activity, interested in their continuing education and improvement. Russia's integration into the world community increases the individual's ability to choose his / her educational and professional path, which increases the level of academic and, consequently, professional mobility. "Training of a competent specialist in the field of design is of strategic importance in the provision of leading industries and social culture with highly qualified professionals. This, in turn, allows us to talk about the focus of the higher professional education system on the quality of designer training, the definition of new lines of development of domestic design education, among which the focus on national cultural values is decisive" [5].

The specificity of professional training of designers requires portraying, for example, still life in certain spatial boundaries of the interior. Portraying still life, it is necessary to know the laws of visual perception of space, as well as the rules by which the artist builds it on the depicted plane.

At the present stage of development to replace the traditional canons of artistic image solutions in the field of design come extraordinary experimental solutions. Author's, exclusive works of various design solutions displace the same type of samples. Design is always "serving the needs of a person and at the same time satisfying his aesthetic needs, bringing beauty to life, reveals the wide possibilities of its use" [7].

Designers often turn to folk styles of different countries. The role of design, stylization as an artistic method has recently increased, as the need of people to create a stylistically integral, aesthetically significant environment has increased. "The desire to decorate any purely utilitarian object was caused by the people's need for beau- ty" [8]. Very often a creative source is the material culture of the peoples. Having distinguished itself as a kind of aesthetic activity, design remains an element of the material production system, one of its necessary elements subordinated to the General laws of its functioning [9]. Design, like any other art form, develops, "stylistically evolves, with successive styles experiencing periods of origin, maturity and decline" [10]. The purpose of design, in the end, is the production of material values, which on the basis of artistic design and acquire aesthetic value.

Such graphic means of drawing, graphics, as spatial volume, color, line, texture, thanks to a certain organization, the designer acquires an individual character and style decision.

The style of the work carries the features of marginal or regional design, which are transformed at the individual level of creativity of a particular person. According to Rosenson I. "Style is a successful intersection of civilization and culture" [11]. The style of the work arises when in the designer's thinking there is a transformation into a certain design construct that is not belonging to any aesthetic or national product, as a result of which the depicted object acquires a new reality. The analysis of sources shows that" the original image... is always collective, i.e. it is common, at least, for the whole peoples and epochs " [12].

The language of the art form of design is characterized by stylistic generality, revealing in the image the characteristic features of other arts, transmitted through stylization and the introduction of further enriching the image of patterned elements. Forming a cultural space, man carries out his way of seeing the world [13].

The problem of improving the professional training of the designer is multifaceted. Higher education institution is designed to produce specialists with a guaranteed willingness to be true professionals. The system of training in higher education is aimed at creating the prerequisites for the versatile professional development of the designer's personality, which include not only the amount of knowledge, but also the ability to master knowledge and skills in the types and methods of theoretical and practical activities that allow further formation and development of creative abilities. The field of training of designers is interconnected with a variety of related disciplines. This integrated approach "calls for a comprehensive examination and consideration of all the factors that contribute directly or indirectly to the problem" [14].

Design is an element of the system of material production, one of the necessary links, subject to the General laws of its functioning.

\section{Conclusion}

To solve many practical issues of using modern research methods: the method of modelling and combinatorics, structural analysis, organization and natural environment etc. In the process of professional training of students - future designers as the degree of personal acceptance of social and cultural values. "None of the great epochs in the development of culture can be recreated anew... but the very memory of the brilliant creations of distant predecessors, an attempt to penetrate into the essence of their plans and achievements are fruitful" [15].

Accordingly, having formed and determined the internal and external contradictions of design education, an algorithm of successive, step-by-step solutions to the problem with a specific diagnosis of the process on each vector of development appears.

\section{References}

[1] Burovkina LA, Dubrovin VM, Valikzhanina SV, Titov AA (2017), Formation of professional competencies in future teachers-artists in the process of mastering the educational program. Art and Education 6 (110), pp: 131-140.

[2] Arnheim R (2007), Art and visual perception. Moscow, Architecture-S, $392 \mathrm{p}$. 
[3] Prischepa AA (2013), Basics of theory and practice of design and arts and crafts: Textbook. allowance. Rostov-on-Don, Pechatnaya Lavka, 239 p.

[4] Prischepa AA (2015), Aspects of the formation of the artistic traditions of Russia at the turn of the century (late XIX and early XX centuries). Izvestia RGSU (materials of the South Russian Forum "Architecture, design and art in the space of culture"), No. 19, pp: $230-234$

[5] Prischepa AA, Vlasova IM (2017), Formation of professional competence of students of designers by universal methods of archetype isostructures: monograph. Rostov-on-Don, Foundation, $373 \mathrm{p}$.

[6] Kantor K (1996), Public nature of design. Decorative Arts USSR 10, pp: 2.

[7] Koreshkov VV, Novikova LV (2015), Design in the educational field "Art". Fundamental and Applied Sciences Today: Materials of the V International Scientific Practical. conference on March 30-31, 2015, North Carleston, USA, pp: 30-35.

[8] Burovkina LA (2016), Basics of arts and crafts: monograph. Moscow: MCPU, 204 p.

[9] Soviet Encyclopedic Dictionary (1990). Moscow: Soviet Encyclopedia.

[10] Yakovleva NA, Mozgovaya EB, Chagovets TP, etc. Yakovleva NA (Ed.) (2005), Analysis and Interpretation of Works of Art: Tutorial. Moscow, Vysshaya Shkola, $551 \mathrm{p}$.

[11] Rozenson IA (2013), Fundamentals of the theory of design. 2nd ed. St. Petersburg, Peter Press, 256 p.

[12] Jung CG (1976), Collected Work, esp. 4, 5, 6, 7, 8, 13, 16. New York: Pantheon Books lnc., Bollingen Foundation lnc.

[13] Taylor EB (1989), Primitive culture. Moscow: Politizdat.

[14] Prischepa AA (2015), Some aspects in the professional training of environmental designers. Modern trends in the development of fine, arts and crafts and design: Collection of articles. FGBOU HPE "NGPU", pp: 166-169.

[15] Neklyudova MG (1991), Traditions and innovation in the Russian art of the end of the X1X-the beginning of the XX century. Moscow, Art, 396 p. 